\title{
Effectiveness of Nano Silver Sulfadiazine and Silver Sulfadiazine on the Growth of Germ Colonies in Deep Dermal Burns
}

Ronald Gestano $^{1}$, Iqmal Perlianta ${ }^{1 *}$

${ }^{1}$ Department of Surgery, Faculty of Medicine, Universitas Sriwijaya

*Correspondence Author Email: iqmalparlianta@gmail.com

\begin{abstract}
Introduction. Secondary infection is one of the most serious complications and the leading cause of death in burn patients. Silver sulfadiazine (SSD) is the standard topical antimicrobial for burns for the past several decades. At present, nano sized silver particles in sulfadiazine nano silver packages have a high surface to volume ratio and remain effective in low concentrations and minimize silver toxicity to tissues.

Methods. This study was a prospective parallel open-label randomized controlled clinical trial. This research was conducted in the Plastic Surgery Subdivision of the Muhammad Hoesin General Hospital Palembang Section from May to September 2018. Deep-dermal burn patients were given random therapy of sulfadiazine and silver sulfadiazine nanosilver. Examination of the number of pre-treatment and post-treatment burn colonies was carried out at the Microbiology Laboratory of Muhammad Hoesin Hospital Palembang.

Results. Profile of patients with deep-dermal burns at RSMH are male (76.7\%), age group between 15-54 years (66.7\%), employees (30\%), burn area <20\% (66.7\%), and caused by fire $(56.7 \%)$. There were differences in the mean number of pre and post-treatment colonies in the sulfadiazine nanosilver group, but there were no differences in the mean number of pre-and post-treatment colonies in the silver sulfadiazine group. The mean number of post-treatment colonies in the sulfadiazine nanosilver group was lower than the silver sulfadiazine group, but there were no significant differences in the number of germ colonies in the two groups.
\end{abstract}




\section{SSS SRIWIJAYA JOURNABOFSURGERУ}

Conclusion. Sulfadiazine nanosilver is effective in reducing the number of germ colonies in patients with deep-dermal burns compared to silver sulfadiazine.

Keywords. Deep-dermal burns, sulfadiazine nano silver, silver sulfadiazine

\section{Introduction}

Secondary infection is one of the most serious complications and the leading cause of death in burn patients. After the initial period of shock, burn infection is the most common complication. ${ }^{1}$ Infection accounts for $75 \%$ of all burn patient deaths with a total body surface area of more than $40 \%$. Infection is a major problem in treating burns because it slows normal wound healing by prolonging the inflammatory phase of the immune response. Necrotic tissue accumulation in the wound area is a source of nutrition for bacterial growth. ${ }^{2}$ Infection of microorganisms on the surface of the burn causes delayed or not healing of burns. ${ }^{3}$ Therefore, appropriate antibacterial therapy must be started on time to avoid serious damage. ${ }^{4}$

Local vascular thrombosis and severe inflammatory responses cause the inability of systemic administration of antibiotics for local infections so that the efficacy of a single intravenous antibiotic to control bacterial reproduction in burns is unsatisfactory. In addition, long-term use of antibiotics can cause multiple drug resistance and superinfection. Early application of topical antibacterial or bactericidal agents is an effective method that can protect burns from bacterial infections and stimulate wound healing. ${ }^{2}$

Antimicrobial silver-carrying preparations have been widely used as topical antimicrobial agents in burns for decades. Silver has a synergistic effect with sulfadiazine in inhibiting bacterial growth. ${ }^{5}$ Silver sulfadiazine (SSD) is a drug that has been approved by the Food and Drug Administration (FDA) as a topical agent for controlling bacterial infections in second-degree burns. SSD plays an important role in inhibiting the molecular transport system, decreasing DNA stability, and decreasing bacterial replication. In addition, SSD has antimicrobial properties by destroying the molecular structure of bacteria and increasing the production of inactive and insoluble metabolites. These metabolites further prevent bacterial infections, eliminate local inflammatory reactions, and stimulate wound healing. 


\section{SSS SRIWIJAYA JOURNABOFSURGERУ}

The use of SSD is recommended for burns with bacterial contamination, clinically showing signs and symptoms of bacterial infection, second and third degree burns, and first degree burns with a large area of the wound. ${ }^{6}$ However, SSD has some fairly serious side effects, such as argiria, leukopenia, liver and kidney toxicity. ${ }^{2,5,7,8}$ Therefore, better therapeutic options are needed in the management of burns.

The discovery of nanotechnology allows the conversion of silver metal into the form of nanoparticles. Nano-sized silver particles are more effective than the original form against microorganisms, thus allowing more effective and better tolerated topical silver therapy. ${ }^{2}$ This small size is beneficial in that it is better able to penetrate into the wound and kill bacteria more quickly. The development of silver in the form of nanoparticles significantly reduces the time needed for the wound area to reach normal homeostatic equilibrium, decreases the risk of unwanted complications, and improves physical appearance of the scar by reducing hypertrophic scar formation. ${ }^{5}$ Most studies report that silver nanoparticles are safe and non-cytotoxic in nature. Nevertheless, the toxicity of silver can be found in the form of argyria. In addition, recent studies have reported potential toxic effects on human fibroblasts, keratinocytes, and mesenchymal stem cells. $^{7,8}$

There have been several clinical trials comparing the effectiveness of silver nanocrystalline compared to other silver for burns. Nherera et al conducted a meta-analysis to evaluate 8 clinical trials comparing the effectiveness of silver nanocrystalline compared to silver nitrate and silver sulfadiazine for burns. The parameters evaluated were the incidence of infection, the length of stay, and the required surgical procedures. The results obtained are: in the group of patients who received silver nanocrystalline the incidence of infection was lower, shorter hospital stays, and fewer surgical procedures were needed. ${ }^{9}$ Liu, et al reported that nanosilver more significantly stimulated healing of second-degree burns, reducing the incidence of infection secondary bacteria, and reduced VAS scores compared to silver sulfadiazine.4 However, there have been no studies comparing the effectiveness of SSDs with SSD nanoparticles (NSSD) in reducing colony of microorganisms in burns. To get better outcomes in the treatment of second-degree burns, efforts need to provide more effective therapies, so research is needed to compare SSD as a standard therapy with NSSD. 


\section{STS SRIWIJAYAJOURNAB OFEURGERY}

\section{Methods}

This study is a prospective parallel open-label randomized controlled clinical trial to compare the effectiveness of therapy between topical sulfadiazine nanosilver and topical silver sulfadiazine in inhibiting the growth of germ colonies in deep dermal burns. Research subjects (30 people) were all deep dermal burn patients who met the inclusion and exclusion criteria. Inclusion criteria were that deep dermal burns were diagnosed based on clinical appearance and physical examination in the form of spotted red color, may or may not be found bullae, capillary filling was absent, and pain sensation was absent and agreed to follow the study as evidenced by informed consent. Exclusion criteria are allergies to one component of silver sulfadiazine, patients with a history of diabetes mellitus or are known to have diabetes mellitus, the patient died during treatment.

Examination of germ colony growth in burns, begins with taking the first specimen swab, Levine technique; Swabs are taken on the wound surface, before being given topical antibiotics, on day $1(\mathrm{t}-0)$ and on day $4(\mathrm{t}-1)$ with a skin surface area of a radius of $10 \mathrm{~cm} 2$ within 5 seconds. The swab is taken in duplicate. The tip of the swab was broken and put into a sterile transport tube which was given $5 \mathrm{~mL} \mathrm{NaCl} 0.9 \%$. The specimen is planted on a blood agar medium. All petri dishes containing specimens were incubated in an aerobic $37{ }^{\circ} \mathrm{C}$. After 24 hours the growth of germs was seen and the number of germ colonies was counted. Colony Forming Unit (CFU) is used to determine the total number of bacteria in each petri dish. Counting the number of germs is done indirectly by counting the number of colonies of germs that grow on agar plates. The number

of germs is calculated from the colonies that grow on the plate so that the medium is multiplied by the dilution or dilution factor, which is $10^{3}$. In this study no dilution or dilution was conducted. The number of bacteria in each colony unit is $10^{2}-10^{3}$ bacteria.

All data obtained is recorded and coded according to needs and then performed data entry using SPSS software version 18.0. The data will be presented in tabular and graphical form. Variable sociodemographic and clinical characteristics, effectiveness and side effects of the drug are expressed in terms of number and percentage or average and standard deviation. All variables were analyzed descriptively by presenting tabulated data and statistically analyzed. Statistical analysis was performed using unpaired t-tests for independent samples, paired t-tests for dependent 


\section{SIS SRIWIJAYA JOURNAB OFEURGERY}

samples, and $\mathrm{x}^{2}$ analysis to compare the characteristics of two groups. Probability value $(\mathrm{p}) \leq 0.05$ is considered significant.

\section{Results}

Most of the samples were male (76.7\%). Based on the age frequency distribution of 30 study samples, the majority of samples aged between $15-54$ years were 20 people $(66.7 \%)$, with an average age of $24.73 \pm 16.913$ years with the youngest age of 2 years and the oldest age of 58 years. Based on the type of work, the majority of the sample (30\%) worked as employees. Based on the area of the burn, more than half the sample had a burn area of $<20 \%$. Based on the cause of burns, fire and explosion were the most causes of burns cases in this study with a percentage of $56.7 \%$.

Table 1. Frequency distribution of research subjects

\begin{tabular}{lcc}
\hline & Characteristic & \multicolumn{2}{c}{ Sample } \\
\cline { 2 - 3 } Sex & N & \\
\hline Male & 23 & 76,7 \\
Female & 7 & 23,3 \\
\hline Age (years) & & \\
\hline$<1$ & 0 & 0 \\
$1-4$ & 5 & 16,7 \\
$5-9$ & 4 & 13,3 \\
$10-14$ & 0 & 0 \\
$15-54$ & 20 & 66,7 \\
$55-64$ & 1 & 3,3 \\
$>64$ & 0 & 0 \\
\hline Occupation & & \\
\hline Labour & 1 & 3,3 \\
Housewives & 3 & 10 \\
Entrepreneur & 3 & 10 \\
Student & 6 & 20 \\
Employee & 9 & 30 \\
No employment & 8 & 26,7 \\
Others & 0 & 0 \\
\hline Clinical condition & & \\
\hline Burn surface area & & \\
\hline$<20 \%$ & 20 & 66,7 \\
20-50\% & 9 & 30 \\
& & \\
\hline
\end{tabular}




\section{STS SRIWIJAYA JOURNAB OFEURGERY}

\begin{tabular}{lcc}
$>50 \%$ & 1 & 3,3 \\
\hline Burn Causes & & \\
\hline Fire & 17 & 56,7 \\
Hot water & 5 & 16,7 \\
Skin contact & 0 & 0 \\
Chemical & 4 & 13,3 \\
Friction & 0 & 0 \\
Electrical & 4 & 13,3 \\
\hline
\end{tabular}

Table 2. Comparison of therapeutic effectiveness in the silver sulfadiazine and nanosilver sulfadiazine pre-therapy and post-therapeutic groups

\begin{tabular}{|l|c|c|c|c|c|c|}
\hline \multirow{2}{*}{\multicolumn{1}{|c|}{}} & \multicolumn{2}{|c|}{ Nanosilver sulfadiazine } & \multicolumn{3}{c|}{ Silver sulfadiazine } \\
\cline { 2 - 7 } Variable & $\begin{array}{c}\text { Pre } \\
\text { therapy }\end{array}$ & $\begin{array}{c}\text { Post } \\
\text { therapy }\end{array}$ & $\mathrm{p}$ & $\begin{array}{c}\text { Pre } \\
\text { therapy }\end{array}$ & Post therapy & $\mathrm{p}$ \\
\hline $\begin{array}{l}\text { Number of } \\
\text { colonies }\end{array}$ & $74.340,73$ & $1.366,67$ & 0,000 & $69.613,6$ & $33.573,33$ & 0,439 \\
\hline
\end{tabular}

Paired $\mathrm{t}$ test; $\mathrm{p}=0,05$

The unpaired t test results in table 2 show that there was no significant difference in the average number of pre-treatment germ colonies between the sulfadiazine and silver sulfadiazine nanosilver groups $(p=0.893 ; p>0.05)$. Based on the paired t test results in table 3 , there were differences in the mean number of pre and post-treatment colonies in the sulfadiazine nanosilver group ( $\mathrm{p}=0,000 ; \mathrm{p}<0.05)$, but there were no differences in the mean number of pre-and posttreatment colonies in the silver sulfadiazine group $(\mathrm{p}=0,000 ; \mathrm{p}<0.05)$, but there were no differences in the mean number of pre-and post-treatment colonies in the silver sulfadiazine group $(\mathrm{p}=0,000 ; \mathrm{p}<0.05) \cdot \mathrm{p}=0.439 ; \mathrm{p}>0.05)$. The mean number of post-treatment colonies in the sulfadiazine nanosilver group was lower than the silver sulfadiazine group, but there were no significant differences in the number of germ colonies in the two groups $(p=0.35 ; p>0.05)$. 


\section{SIS SRIWIJAYA JOURNAB OFEURGERY}

\section{Discussion}

In this study, found a male gender prediction that experienced deep dermal burns with a percentage of $76.7 \%$ and a ratio of 3.3: 1. This is in line with studies that report male sex predominance with each ratio 1.22: 1, 2: 1, 2.26: 1, and 2.5: 1 in burn cases. Men are considered to be more active and mobile so it is easier to experience a high risk of burns related to the environment and work. ${ }^{10-13}$

Most (66.7\%) burn patients aged between 15-54 years with a mean age of $24.73 \pm 16.913$ years with the youngest age of 2 years and the oldest age of 58 years. The results of this study are not much different from other studies. Wardhana et al reported that approximately $68.6 \%$ of patients were over 18 years of age with a median age of 29.31 (0.67-76). A study stated that burns were most often found in the age group between 15 and 54 years $(68 \%) .{ }^{14}$ Studies reported that the incidence of fire and electric burns was most age group between 25-65 years. This age group generally has activities related to fire and electricity so that the incidence rate of burns is high in this age group. ${ }^{15}$ Most (30\%) burn patients in this study were employees. This is different from the study of Wardhana et al. Who reported that the majority of the adult population of burn patients were laborers. Workers are more vulnerable to occupational hazards that can cause burns, such as factory explosions and power plants. ${ }^{16}$

Burn area $<20 \%$ is the most common burn area in this study with a percentage of $66.7 \%$. This is different from other studies. Wardhana et al reported that almost half of burn patients treated had burns between 11-30\% ${ }^{17}$ Studies reported that the most extensive burns were between $20-50 \%$ with a percentage of $45.87 \% .{ }^{18}$ Other studies reported that the mean area of burns in children and adults is $25 \%$ and $40 \%$, respectively. Burn area is a risk factor for mortality and an important indicator in the management strategy of burn patients. The more extensive the burn, the higher the death rate. ${ }^{19}$

The cause of deep dermal burns in this study was fire. Similar results were reported by studies that reported that fire was the main cause of the most common burns with $48.3 \%, 55 \%$ and $59.4 \%$, respectively. Fire and explosion are the main factors that cause death in burn patients because the effects of fire and explosion affect the breadth and depth of the burn. The heavier and more extensive, the higher the morbidity and mortality rate. ${ }^{20}$ Most households in Indonesia use liquefied natural gas (LPG) as a fuel source for cooking. Fire and explosion burns are also related 
to the use of LPG at home and lack of vigilance or education, especially in the prevention of burns. The increase in the incidence of fire burns is also thought to be related to several factors, such as socioeconomic background and education. ${ }^{21}$

Based on the results of statistical tests, the mean difference in the number of pre and posttreatment colonies in the sulfadiazine nanosilver group, but there were no differences in the average number of pre-and post-treatment colonies in the silver sulfadiazine group. The mean number of post-treatment colonies in the sulfadiazine nanosilver group was lower than the silver sulfadiazine group, but there were no significant differences in the number of germ colonies in the two groups. The average difference in the number of germ colonies between silver nanoparticles and negative controls was reported by Jeong et al. Jeong, et al reported that silver nanoparticles in doses of $10 \mathrm{~nm}$ and $100 \mathrm{~nm}$ per $1 \mathrm{mg} / \mathrm{mL}$ showed antimicrobial activity against Methylobacterium spp. which is equivalent to a positive control (methanol) with a colony number of $4 \times 10^{2} \mathrm{CFU}$ compared to a negative control $\left(1 \times 10^{8} \mathrm{CFU}\right) .^{22}$

The reduction and average difference in the number of pre and post colony colonies in the sulfadiazine nanosilver group showed potential in reducing the number of germ colonies in deep dermal burn patients. This potential is due to the fact that nanocrystalline silver has advantages over other silver preparations because it is pure silver, has no compound, and has a very small particle size, smaller than silver nitrate or silver sulfadiazine. The discovery of nanotechnology allows the conversion of silver metal into the form of nanoparticles. Nano-sized silver particles are more effective than the original form against microorganisms, thus allowing more effective and better tolerated topical silver therapy. ${ }^{2}$ This small size is beneficial in that it is better able to penetrate into the wound and kill bacteria more quickly. The development of silver in the form of nanoparticles significantly reduces the time needed for the wound area to reach normal homeostatic equilibrium, decreases the risk of unwanted complications, and improves physical appearance of the scar by reducing hypertrophic scar formation. ${ }^{5}$ Most studies report that silver nanoparticles are safe and non-cytotoxic in nature. ${ }^{23}$

Silver ions play a role in the antibacterial activity of silver nanoparticles. Silver ions can bind to cell wall sulfohydryl groups. Sulfohydryl groups in the enzyme system can be degraded by the conjunction of silver ions. Conjugated silver ions can prevent the formation of energy and electron 


\section{SSS SRIWIJAYA JOURNABOPSURGERY}

transport in cells. Silver ions are also reported to damage the respiratory system of bacteria by conjugating the proteins involved in the process. ${ }^{24}$

Several studies report the broad-spectrum antibacterial and antifungal effects of nanocrystalline silver. Nanosilver has broad-spectrum antimicrobial effects on bacteria, including Clostridium perfringens, Staphylococcus aureus, Enterobacter, and Candida albicans. The antibacterial mechanisms of silver nanocrystalline include bacterial cell wall disruption, blockade of DNA replication, and deactivation of important enzymes in the bacterial respiratory system. Therefore, silver nanocystalline is an effective barrier to microbial invasion and significantly reduces the risk of infection. Ionized silver and silver nanoparticles exhibit antibacterial, antifungal effects and their use as a coating on various medical devices can prevent biofilm formation by pathogenic bacteria. ${ }^{4}$ Nanocrystalline silver-based dressings are proven to have the most rapid and extensive fungicidal activity compared to other wound dressings (including which contains silver nitrate and silver sulfadiazine). This dressing has been proven to be able to overcome several problems related to previous wound dressing, such as tissue irritation and narrow spectrum antifungal effects. Nanoparticles also exhibit antiretroviral activity and inhibit dose-dependent HIV-1 replication. ${ }^{25}$

\section{Conclusion}

Sulfadiazine nanosilver is effective in reducing the number of germ colonies in patients with deep-dermal burns compared to silver sulfadiazine.

\section{References}

1. Naqvi SQA, Naqvi SMA, Usman M. Burn wound infection: significance of rule of nine in microbial surveillance.Professional Med J 2014;21(5): 869-873.

2. Adhya A, Bain J, Ray O, Hazra A, Adhikari S, Dutta G, et al. Healing of burn wounds by topical treatment: randomized controlled comparison between silver sulfadiazine and nanocrystalline silver. Basic Clin Pharm. 2014; 6(1): 29-34. 


\section{STS SRIWIJAYA JOURNABOFEURGERY}

3. Al Laham NA, Elmanama AA, Tayh GA. Possible Risk Factors Associated with Burn Wound Colonization in Burn Units of Gaza Strip Hospitals, Palestine. Annals of Burns and Fire Disasters 2013; 26(2):68-75.

4. Venkataraman M, Nagarsenker M. Silver sulfadiazine nanosystems for burn therapy. AAPS Pharm Sci Tech 2013; 14(1):254-64.

5. Liu Z, Zhou A, Zhang X et al. The efficacy of nano-silver and silver sulfadiazine for degree II burn wound:a meta-analysis. Biomed Res 2017; 28 (9): 3880-3885.

6. Munteanu A, Florescu IP, Nitescu C. A modern method of treatment: the role of silver dressings in promoting healing and preventing pathological scarring in patients with burn wounds. J Med Life. 2016; 9(3):306-315.

7. Konop M, Damps T, Misicka A, Rudnicka L. Certain Aspects of Silver and Silver Nanoparticles in Wound Care: A Minireview. Journal of Nanomaterials. 2016; 1: 1-10.

8. Silver S. Bacterial silver resistance: molecular biology and uses and misuses of silver compounds. FEMS Microbiology Reviews. 2003; 27: 341-353.

9. Nherera LM, Trueman P, Roberts CD, Berg L. A systematic review and meta-analysis of clinical outcomes associated with nanocrystalline silver use compared to alternative silver delivery systems in the management of superficial and deep partial thickness burns. Burns. 2017;43(5):939-48.

10. Pujisriyani P, Wardana A. Epidemiology of burn injuries in Ciptomangunkusumo hospital from 2009 to 2010. JPR Journal. 2012; 5(3): 528-531.

11. Wardana A, Basuki A, Prameswara ADH, Rizkita DN, Andarie AA, Canintika AF. The epidemiology of burns in Indonesia's national referral burn center from 2013 to 2015. Burns Open. 2017; 1: 67-73.

12. Moenadjat Y, dkk. Luka Bakar. Edisi I. Jakarta: Balai Penerbit FKUI; 2008. h.

13. The Education Committee of Australian and New Zealand Burn Association. Emergency Management of Severe Burns. $18^{\text {th }}$ Ed. ANZA: Queensland; 2016. p. 52-57, 117-120.

14. Hettiaratchy S, Dziewulski P. Pathophysiology and types of burns. BMJ 2004; 12:1427-1429.

15. Brunicardi FC, Anderson D, Dunn DL. Schwartz's Principles of Surgery. $8^{\text {th }}$ Edition. New York: McGraw-Hill; 2005. p. 


\section{SSS SRIWIJAYAJOURNABOPSURGERY}

16. John OL, David NH. Burn and Radiation Injuries. In: Trauma. $6^{\text {th }}$ Ed. New York: Mc Graw Hill; 2008. p. 1051-1074.

17. Hoogewerf CJ, Hop MJ, Nieuwenhuis MK, Middelkoop E, Van Baar ME. Early excision and grafting for burns (Protocol). Cochrane Database of Systematic Reviews 2012; 3: 1-15.

18. Hamdan S, Pastar I, Drakulich S, Dikici E, Tomic-Canic M, et al. Nanotechnology-Driven Therapeutic Interventions in Wound Healing: Potential Uses and Applications. ACS Cent Sci. 2017 22; 3(3): 163-175.

19. Gallagher JJ, Branski LK, Bouyer NW, Villarreal C, Herndon DN. Treatment of infection in burns. In: Total Burn Care. New York: ElSevier; 2012. p. 137-142.

20. Manson WL, Pernot PCJ, Fidler V, Sauer EW, Kalasen HJ. Colonization of burns and the duration of hospital stay of severely burned patients. J Hosp Infec 1992; 22 (1):55-63.

21. Norbury W, Herndon DN, Tanksley J, Jeschke MG, Finnerty CC. Infection in Burns. Surgical Infections. 2016; 17(2): 250-255.

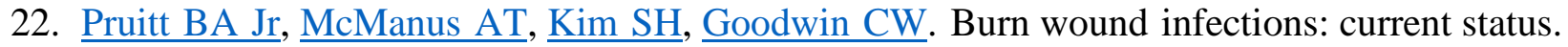
World J Surg. 1998 Feb;22(2):135-45.

23. Church D, Elsayed S, Reid O, Winston B, Lindsay B. Burn Wound Infections. Clinical Microbiology Reviews. 2006; 19(2): 415-418.

24. Campos J, Namara MM, Howard B. Specimen Collecting and Processing. St.Louis: Mosby Elsevier; 1994. P.

25. Fuller FW. The Side Effects of Silver Sulfadiazine. Journal of Burn Care \& Research 2009; 30(3): 464-470. 